\title{
Chamanismo, liderazgo y poder indígena: el caso tsachila ${ }^{1}$
}

\author{
Montserrat Ventura i Oller \\ Universitat Autònoma de Barcelona (España) \\ Montserrat.ventura@uab.cat
}

Recibido: 17 de enero de 2011

Aceptado: 12 de abril de 2011

\begin{abstract}
RESUMEN
El presente artículo recorre brevemente el pasado preinca y colonial y repasa la mitología para delinear el sistema político tradicional del grupo indígena tsachila de la costa ecuatoriana, donde habrían existido dos figuras de poder, el líder político y el chamán, a veces superpuestas en una sola persona. A continuación la autora analiza en detalle las formas políticas contemporáneas de esta sociedad, desde el momento del establecimiento de las comunas y la gobernación tsachila, para concluir que las formas actuales son parcialmente herederas de las anteriores y que el conocimiento de éstas es necesario para comprender el lugar de esta sociedad en la política indígena nacional.
\end{abstract}

Palabras clave: Ecuador, tsachila, sistemas políticos indígenas, poder indígena, chamán.

\section{Shamanism, Leadership and Indigenous Power: the Tsachila Case}

\begin{abstract}
This paper covers briefly the pre-Inca and colonial past and examines the mythology to outline the traditional political system of the indigenous group Tsachila of the Ecuadorian coast, which would have been two power figures, the political leader and the shaman, sometimes represented by a single person. Then the author analyzes in detail the contemporary political forms of this society, from the time of establishment of the communes and the Gobernación Tsachila, concluding that the current forms are partly inherited from the past and that knowledge of these is necessary to understand the place of this society in the national indigenous policy.
\end{abstract}

Key words: Ecuador, Tsachila, indigenous political systems, indigenous power, shaman.

Sumario: 1. El gobierno indígena en la historia. 2. Las figuras del poder en la actualidad. 3. Los tsachila y el Estado. 4. Relaciones con la CONAIE. 5. Reflexiones finales. 6. Referencias bibliográficas.

El movimiento indígena ha sido ampliamente estudiado desde la perspectiva social y política. En estos análisis no han faltado las discusiones en torno a la articulación de las grandes federaciones con las organizaciones de base y los poderes locales. Por

1 Este texto es la actualización de una ponencia discutida en su versión preliminar en el seminario «El Ecuador en crisis: etnicidad, estado y movimientos sociales en la era de la globalización», organizado por el Grupo Interdisciplinario de Estudios de Desarrollo y Multiculturalidad (GIEDEM) de la Universitat de Lleida el 20 de Noviembre del 2001. Agradezco a los asistentes sus comentarios y particularmente a Víctor Bretón, organizador. Agradezco también a Manuel Gutiérrez Estévez y Julián López García el impulso final para su publicación. 
otro lado, ejemplos paradigmáticos para la opinión pública, como el ostracismo local hacia líderes tan mediáticos como el conocido Raoni (kayapo, Amazonía brasileña), han dado lugar a múltiples interpretaciones sobre la dificultad de liderazgo étnico local para actores políticos a escala global, cuando éstos necesariamente deben alejarse de sus realidades folk para desenvolverse con dignidad en las arenas políticas de corte occidental ${ }^{2}$. Ello es particularmente acuciante en el caso de las organizaciones étnicas de las tierras bajas, donde el colonialismo ha penetrado de forma tardía si lo comparamos con la región andina.

La energía y la capacidad de respuesta demostradas en las últimas décadas por la Confederación de Nacionalidades Indígenas del Ecuador (CONAIE) han convertido a esta federación en un ejemplo de organización política indígena para todo el continente americano e incluso para los movimientos de resistencia y lucha aborigen de todo el mundo. La CONAIE presenta una particularidad respecto de otras organizaciones indígenas, a saber, no sólo la variedad de grupos étnicos a los que representa, fruto de la riqueza étnica ecuatoriana, sino también la extrema diversidad entre éstos. La separación geográfica del Ecuador en Sierra, Costa y Amazonía está en estrecha correlación con la diferencia cultural entre estas distintas regiones, a la que se une la diversidad de formas políticas tradicionales. Mientras que los Andes llegaron a formar parte de grandes imperios, de sociedades prácticamente estatales, los cacicazgos étnicos y las grandes civilizaciones que se desarrollaron en las tierras bajas, en la Costa y en la Amazonía, mantuvieron sistemas políticos cuyo talante igualitario, aun siendo objeto de debate (cf. Clastres 1974; Descola 1988; Roosevelt 1993), imprime a estas sociedades unas características diferentes a las sociedades andinas, claramente más jerarquizadas. A todo ello hay que añadir la distinta influencia de la colonización, española primero e interna después, en estas áreas indígenas. Mientras que en los Andes los sistemas de cargos políticos se institucionalizaron en momentos bien tempranos de la Colonia, no es aparentemente hasta mediados del siglo XIX en que las figuras de representación colonial en el medio indígena de las tierras bajas manifiestan su influencia de forma relativamente marcada en el ámbito local. El gobierno indirecto propio de la Colonia, ejercido en estas regiones periféricas por personajes designados por las Misiones, no llegó a transfigurar de forma significativa la organización cotidiana de los grupos étnicos amazónicos y del occidente ecuatoriano, fuera de los límites de la frontera de colonización, donde la transformación fue tan drástica que llevó a la desintegración de muchas de estas etnias.

En las páginas que siguen vamos a analizar el caso del grupo indígena tsachila de la costa del Ecuador ${ }^{3}$. Se trata de uno de los grupos con menos participación colectiva en el movimiento indígena nacional y uno de los grupos cuya aparente desunión interna fue por un tiempo más destacada. Sin embargo, más que un contraejemplo de la unidad indígena, este caso nos ayudará a reflexionar sobre la difícil articulación entre las realidades micro y macro del movimiento político indígena a la que aludíamos con anterioridad. Para entenderlo, debemos recurrir necesariamente a la historia y a la

\footnotetext{
2 En este sentido, ver la compilación de López García y Gutiérrez Estévez (2009) o los trabajos sobre mediación indígena de Kradolfer (2011a y 2011b), Martínez Mauri (2009 y 2010) y Martínez Mauri y Rodriguez Blanco (2008).

3 Para una introducción general a este grupo, ver Ventura 1997,1999 y 2009.
} 
etnografía, a la perspectiva temporal y al análisis minucioso de la realidad cotidiana contemporánea.

\section{El gobierno indígena en la historia}

Es difícil determinar el sistema de gobierno tsachila en la época pre-inca. Según los restos arqueológicos y algunos trabajos comparativos con el área cultural barbacoa, parece que la figura de prestigio por excelencia era el chamán. Marcos $(1988,2005)$ señala la existencia de líderes con poder terrenal y chamánico documentados arqueológicamente en sociedades geográficamente próximas, como en Real Alto. En un estudio comparativo de distintos yacimientos ecuatorianos, Stothert (2003: 407-408) propone la existencia de un liderazgo claro, que combinaría el poder terrenal y sobrenatural, pero que estaría dedicado a sociedades pequeñas y relativamente distantes una de otras; lo que la autora denomina práctica e «ideología chamánica» habría contribuido a que los pueblos del período Formativo mantuvieran sociedades flexibles y no jerarquizadas, políticamente autónomas, que habrían así evitado algunas formas de centralización política y jerarquización social. Uno de los trabajos etnohistóricos que le precedió (Helms 1980) referido al área cultural circumcaribe, expone a partir de datos antillanos, muiscas, del valle del Cauca y de Panamá, la existencia en todas estas sociedades de dos tipos de sucesión: una determinada genealógicamente y otra, cuando la primera no era posible, marcada por la capacidad de controlar el orden social, natural y sobrenatural. Esta última habría podido ser adoptada como normativa desde la desestructuración de las sociedades indígenas del Pacífico ecuatoriano, de lo que se habría seguido una unificación de roles, político y chamánico, en la misma persona, como parece que se dio entre los antiguos tsachila. En realidad desconocemos cuál era con exactitud el rol social del chamán en la sociedad tsachila, especialmente en cuanto a jefatura política se refiere. Lo que sí sabemos es que el prestigio de sus chamanes en tanto curanderos traspasaba sus fronteras étnicas desde los primeros tiempos de la Colonia.

Por otro lado, la historia posterior a la conquista es rica en documentos que describen el rol de los jefes indios como intermediarios con la sociedad colonial. El historiador jesuita Jouanen (1941: 79) expone la estrategia de elección de jefes indígenas bajo el control de los representantes de la Iglesia con el fin de que lleven a cabo, entre otros, el control de los curanderos y «brujos» ${ }^{4}$, contra los que los jesuitas libraron una dura batalla. A pesar del alcance más bien andino de esta política, de ella se desprende una separación de los roles de chamán y de jefe político, al menos desde la Conquista, que se habría extendido a las tierras bajas. La existencia de una

\footnotetext{
4 «Nuestros padres se valieron también para avezar a los indios a la vida civilizada, de la costumbre ya en uso de nombrar de entre ellos mismos sus autoridades, como gobernadores, alcaldes y aguaciles. Estos nombramientos se hacían fuera de la iglesia con la mayor publicidad posible, en presencia de todos los indios reunidos para el efecto, y de alguna de las autoridades eclesiásticas o civiles. En medio de este concurso, la autoridad civil, cuando la había, o sino el Padre, remitía al indio escogido para dignidad el bastón que era la insignia de su mando y autoridad. Su oficio se reducía a avisar al Padre de cualquier desmán o falta pública que hubiese contra las buenas costumbres, y prender y hacer castigar a los borrachos, brujos o hechiceros» (Jouanen 1941:79).
} 
figura denominada «Gobernador de los Colorados» en el siglo XVIII (Navas 1990: 89) en la región de Angamarca, donde los jesuitas habían establecido su reducción desde el siglo XVI, constituye otro indicio de ello. En la actualidad, varios testimonios orales atribuyen la elección del jefe indígena tsachila a los curas misioneros que visitaban periódicamente la región hacia principios del siglo XX, y confirman su rol de control social externo, como responsables de castigos, especialmente referidos a la trasgresión de la moral cristiana. Esta figura era designada con el término de miya y parece que en ausencia de la inspección clerical, que sólo llegaba una vez por lustro por término medio, su función represiva se mitigaba. En este sentido, parece claro que su rol era incompatible con el de chamán. Sin embargo, cuando se trataba de otorgar su confianza a un líder, la figura elegida por los tsachila era aquella con más prestigio y esta característica era invariablemente atributo de chamanes. Dicho de otra forma, miya significa «el que sabe», y quienes saben de verdad son los chamanes. Con lo que podemos establecer que, fuera del gobierno indirecto colonial, para los tsachila la figura de miya y la de pone (chamán) se superponían. En cuanto a las funciones atribuidas a cada uno de estos personajes, miya y pone, jefe y chamán, debemos señalar que los conflictos situados en un pasado más o menos mítico fueron resueltos de distinta manera: mientras que los conflictos de carácter histórico, como la batalla contra los dobes (personajes históricos, protagonistas de un grupo de mitos) u otros similares, fueron resueltos por los tsachila recurriendo a héroes salvadores externos (como Wela), los problemas evocados por la mayor parte de mitos se zanjan casi invariablemente acudiendo a la sabiduría, buen hacer y capacidad de resolución de los chamanes, sin que se mencione para nada la figura del miya. Y es que, miya o pone, los tsachila confían en una persona dotada de la capacidad de actuar sobre sus destinos, ya sea en el ámbito social o en el cosmológico. Y si el miya sólo puede resolver situaciones conflictivas terrenales, los dos mundos, social y cosmológico, son en cambio igualmente recubiertos por el pone. Ph. Descola (1988) ha sintetizado esta función multidimensional de los chamanes en su crítica al concepto de poder establecido por P. Clastres (1974, 1980), atribuyéndole una definición más abierta y polivalente: «Uno de los atributos más comunes del chamán amerindio es sin duda esta función de control simbólico ejercido sobre ciertos recursos materiales o ideales de los que depende la existencia colectiva»; de ahí, el chamán amerindio sería dotado de un verdadero poder político si aceptamos «que la facultad de aparecer como la condición de la reproducción armoniosa de la sociedad es un componente fundamental del poder político en todas las sociedades premodernas» (Descola 1988: 826). La extensión del poder atribuido a estos personajes en la actualidad, así como su presencia recurrente en el universo mítico, apuntan a la relevancia de la figura de este tipo de líder en distintos períodos de la historia de los pueblos amerindios, aunque mantenemos la prevención ya evocada por otros autores respecto al uso de analogías, tanto en sentido genérico (Vila 2006) como aplicado al estudio del liderazgo indígena en el caso ecuatoriano (Stothert 2003: 343). 


\section{Las figuras de poder en la actualidad}

En la actualidad, el líder político elegido bajo la reglamentación de los Estatutos y de la Ley comunal tiende a ser un pone reconocido, o en su defecto un curandero. El primer gobernador elegido como representante de la entonces llamada Tribu de los Indios Colorados, fue Alejandro Calazacón, chamán, que fue sucedido por su hijo Abraham también chamán (y primero en ser reconocido oficialmente por la Presidencia de la República, en 1971) y este a su vez por su hijo Nicanor. Nicanor asumió el liderazgo en plena juventud, por lo que no había concluido su proceso de aprendizaje como chamán, pero también se dedicaba a curar. Reformados los estatutos en 1996 y sustituida la figura de gobernador vitalicio por otro elegido anualmente por sufragio, el gobernador subsiguiente, Manuel Calazacón, aunque contestado por un sector de la población tsachila, siguió siendo un curandero. No se trataba de un pone ni su cargo era vitalicio ni heredado, pero es uno de los curanderos más conocidos en el exterior y de los económicamente mejor situados de toda la sociedad tsachila, por lo que se le puede atribuir el adjetivo de personaje eminente. Es claro sin embargo que la aparente coincidencia de estas dos figuras de poder, jefe político y chamán, no es sencilla, puesto que tradicionalmente los tsachila vivían en hábitat disperso, formando distintas agrupaciones, cada una de las cuales podía disponer de su figura de prestigio. Los ancianos tsachila recuerdan distintas figuras eminentes que ejercían como chamanes en los últimos cincuenta años del siglo XX. Al contrario de lo que cabría esperar, este multiliderazgo no ha sido reemplazado por los líderes comunales, también elegidos por sufragio anual, ya que los criterios de elección de éstos siguen otra lógica, que detallaremos más adelante. En cambio, en el seno de cada comuna existen individuos relevantes cuya opinión es oída a pesar de no detentar ningún cargo formal, y que por razones diversas ejercen temporalmente el rol de líderes de facto, sin por ello ser chamanes ${ }^{5}$.

J.-P. Chaumeil (1990) y M. Brown (1993) han realizado excelentes análisis sobre el multiliderazgo, la adaptación de los antiguos líderes a la nueva estructura organizativa de las comunidades indígenas en el marco del Estado Nacional y del nuevo contexto político indígena, así como la emergencia de una nueva tipología de liderazgo indígena para el caso amazónico. En general, constatan la emergencia de nuevos líderes, con características distintas respecto de las figuras de poder tradicionales, y que en un gran número de casos entran en contradicción con su filosofía. Ambos autores señalan la dificultad de los nuevos líderes de obtener la plena aceptación de su grupo una vez han desarrollado sus competencias con el mundo exterior, aptitud por la cual fueron elegidos, dado que el aumento de tiempo y adaptación a las forma de vivir y de desenvolverse occidentales les apartan de su tradición, a la que difícilmente regresan. Aunque más adelante veremos cómo entre los tsachila ningún líder ha optado por la proyección exterior -sí lo han hecho personas con cargos institucionales pero sin liderazgo reconocido por el grupo-, de estos trabajos se desprende que el fenómeno descrito más arriba para los tsachila es recurrente en sociedades donde la influencia de la colonización se ha hecho presente de forma acelerada sólo en la segunda parte

\footnotetext{
5 No podemos en este texto abordar el poder cotidiano de los chamanes, ejercido principalmente a través de sus rituales, y de naturaleza distinta al que confieren los cargos políticos actuales. Para una aproximación a este tema ver, entre otros, Ventura (1996b, 2009 y 2011).
} 
del siglo XX. En su mayoría, la presión colonial, la denominada «penetración del estado-nación», ha sido muy débil y sólo se materializó a través de figuras individuales (el viajero, el comerciante, el misionero, el recaudador, el agrónomo), muchas de las veces en situaciones incluso conflictivas respecto del estado-nación al que supuestamente se vinculan. Algo bastante alejado de la presencia colonial más acuciante y permanente que vivieron los pueblos andinos. La frágil presencia del Estado en las sociedades amazónicas y de la vertiente occidental de los Andes es en realidad parte de una situación a mayor escala. Algunos autores han destacado la debilidad de los Estados latinoamericanos y su frágil presencia en la sociedad en general, e incluso que el problema latinoamericano radica justamente en la implantación del modelo republicano francés y su filosofía de estado-nación unitario basado en la autoctonía para considerar el derecho a la ciudadanía precisamente en sociedades donde los autóctonos son relegados de dicha condición (Guerrero 2000; Stolcke 1997).

\section{Los tsachila y el Estado}

La presencia fragmentada del Estado en las sociedades indígenas de las tierras bajas se hace evidente en el caso tsachila. Las únicas instituciones estatales presentes en las comunas de este grupo étnico son la escuela pública y los cabildos comunales. No existen servicios de atención médica. Otro tipo de servicios, públicos o privados, representantes, si no del Estado, sí de la llamada «sociedad nacional», tampoco tienen gran actividad en el medio tsachila: transportes públicos que no cubren las necesidades de movilidad en muchas ocasiones, inexistencia de servicio de agua corriente, de recogida de basuras y de línea telefónica y electricidad precaria. La radio y en menor medida la televisión son quizás los medios de comunicación más usados y últimamente se ha extendido el uso de la telefonía móvil. Aun así, existe un desconocimiento generalizado de la política nacional y una mayoría de tsachila no participa en las elecciones, como tampoco participa en el servicio militar. El ejército sí está presente en su imaginario, representante por excelencia de poder. Hay un destacamento militar cercano, y algunos tsachila influyentes han conseguido compadrazgo con algún oficial. A pesar de no observarse un temor especial hacia ellos, dada la relativa buena consideración de este cuerpo en el conjunto de la sociedad ecuatoriana, los militares aparecen frecuentemente en las visiones de los chamanes, a menudo con el rol de espíritus con poder negativo. En cuanto a las iglesias, que en la América Indígena han sido consideradas como el polo de introducción de la cultura occidental por excelencia desde el período colonial, hay que resaltar que su interferencia es igualmente precaria. En la época colonial, las misiones se desarrollaban por períodos muy cortos y a una distancia temporal entre ellas muy amplia, de unos cinco años ya en el siglo XX, según se desprende de los archivos eclesiásticos. En la actualidad no existe ninguna iglesia católica en las comunas y muy pocos son los tsachila que acuden a los oficios dominicales en el pueblo, al igual que ocurre con las personas de confesión evangélica, y ello a pesar de que una de las comunas, Cóngoma, fue sede de una misión del Instituto Lingüístico de Verano durante varias décadas. De hecho, el contacto más cotidiano con el mundo exterior, fuera de la escuela para la población 
más pequeña, es a partir de los mercaderes ambulantes que diariamente visitan las comunas para ofrecer sus variados productos, y las visitas regulares al recinto poblado más próximo o a Santo Domingo, que realizan distintos miembros de los hogares tsachila para abastecerse. Por otro lado, observamos eventuales desplazamientos de representantes locales, cantonales o provinciales de ministerios de ganadería o salud para informar de planes de desarrollo variados, pero sus estancias se suelen reducir a reuniones con miembros del cabildo comunal o del consejo de la gobernación, por lo que su presencia general es igualmente débil. Lo mismo ocurre con incursiones -todavía menos comunes por cierto- de algún representante de ONG's para el desarrollo, locales, nacionales o internacionales, y algún que otro investigador. Ante esta situación, debemos valorar la eficacia parcial de la escuela y de la organización comunal para comprender la fragilidad del proceso de integración a la sociedad nacional y de la conciencia de ciudadanía, así como -lo veremos en el siguiente apartado-, de la propia conciencia de identidad panindígena.

En todas las comunas tsachila existe una escuela primaria, que acoge en sus dos primeros años el programa intercultural bilingüe, impartido por profesores autóctonos formados para ello. El resto de los cursos está a cargo de profesores del sistema nacional. Son escuelas integradas y se cubren las necesidades del alumnado con escasos enseñantes de cada sistema. Dada la lejanía de los grandes centros poblados, muy pocos son los profesores que deseen las comunas tsachila como destino. Sin embargo, el sistema nacional promueve la aceptación de un destino rural en los primeros años de ejercicio profesional. El producto es un relativo desinterés por parte del joven profesorado destinado a las escuelas tsachila, que se traduce en una disminución del número de horas lectivas y la poca innovación didáctica adaptada a las necesidades específicas de una población indígena hablante de una lengua en retroceso. En cuanto a los contenidos, inspirados en la misma filosofía que los del resto del territorio ecuatoriano, los niños tsachila aprenden muy pronto el himno nacional y los colores de la bandera, que reproducen en múltiples ocasiones, pero el patriotismo ecuatoriano que se busca como resultado no se corresponde con la adquisición de una conciencia de ciudadanía que incluya la plena asunción de los derechos y los deberes de todo ciudadano. Probablemente, el método de aprendizaje memorístico contribuya a la adquisición y no a la comprensión de unos contenidos y de su significado. Por otro lado, los dos años de enseñanza bilingüe, que se limitan a facilitar a los niños tsafikihablantes el paso a la educación en castellano de forma gradual, no son suficientes para ofrecer una especial sensibilización en las cuestiones culturales propias, a pesar del uso de los mitos en algunos de los manuales editados por la Educación Intercultural Bilingüe Tsachila. Hay una escasa sensibilización en la cultura autóctona, y mucha menos concienciación sobre la pertenencia al sector indígena de la sociedad ecuatoriana y la realidad de su lucha. Actualmente la mayoría de familias tratan con mucho respeto las instituciones oficiales, entre las que se cuenta la escuela. Aunque en este sentido las cosas han cambiado, debemos recordar que un sector importante de los líderes tsachila se opuso durante mucho tiempo a la introducción de las escuelas en su comunidad, convencidos de que con ellas entraban los males de la civilización. En las escuelas los niños viven ahora una especie de doble personalidad, pues la realidad cotidiana se transforma completamente en el ámbito escolar, donde pasan a tratar 
con solemnidad a quien por las tardes es vecino o reside en la propia casa, y ven sus nombres igualmente cambiados, pues los nombres de la vida corriente no son los oficiales, los que se usan en el ámbito escolar ${ }^{6}$. La escuela se considera un tentáculo de la sociedad nacional, algo externo que no acaba de penetrar o de entenderse pero que se debe respetar.

Por otro lado, y como expuse en otro trabajo (Ventura 1996a), la organización formal de las agrupaciones tsachila en comunas no se corresponde en absoluto a una forma autóctona de gobierno, ni siquiera de organización del espacio o de la propiedad. El debate en torno a la gestión comunal de recursos en el mundo andino ha sido extenso (Breton 1997; Chamoux y Contreras 1996; Diez 1991; Golte 1992; Urrutia 1992) y la conclusión que podemos sacar, resumiendo, es que se trata del producto de una forma de organización procedente de la metrópoli colonial conjugada con un substrato andino, que en ningún caso se puede asociar a las formas de organización socio-económica y política de las sociedades de las tierras bajas americanas. En el caso ecuatoriano, la Ley de comunas existe desde el año 1937 y en las tierras bajas orientales (amazónicas) y occidentales (costeñas), tierras de colonización dirigida a raíz de la reforma agraria, se empezó a aplicar a mediados del siglo XX. Para los tsachila, se trataba de un mal menor ante la llegada masiva de colonos de otras regiones del país dispuestos a ocupar cualquier pedazo de tierra con apariencia de «baldía», no cultivada, para subsanar su propia supervivencia. Éste era el caso de buena parte de la selva habitada por los tsachila, dado su práctica histórica de la agricultura de tala y quema, que necesita de largos períodos de barbecho, así como su todavía importante recurso a la caza como forma de subsistencia, que requiere de amplios espacios de territorio silvestre. Acostumbrados al hábitat disperso, respondieron a la llamada institucional de formar agrupaciones de familias con el fin de llegar a cincuenta personas, el mínimo establecido para constituirse en comuna según el Artículo 5 de la Ley ecuatoriana de comunas 7 . Las comunas se fueron creando así, entre los años 1954 y 1963. Se trataba de conseguir los títulos de propiedad de la tierra, de forma comunal, con el fin de salvaguardar su territorio de la progresiva penetración de colonos, pero esta política tuvo un efecto perverso dadas sus intenciones: por un lado, el territorio tsachila quedó limitado, reducido y dividido, sus comunas ahora separadas entre sí por parcelas otorgadas a los colonos mestizos. $\mathrm{Al}$ mismo tiempo, fijaba para siempre el hábitat de los tsachila, quienes ya no podrían practicar más la agricultura semi-itinerante y los sucesivos cambios de vivienda propios de su cultura. La reducción y fijación en un área introducía igualmente un sistema de transmisión hereditaria de la tierra, anteriormente inexistente, cuando cada joven pareja dispuesta a emanciparse talaba una nueva parcela de bosque para su cultivo. Las parcelas de cada comunero quedaron limitadas a las hectáreas cultivadas en el momento de la legalización de las comunas.

Lejos de convertir sus bienes en comunales, los tsachila siguieron trabajando y considerando sus parcelas de tierra de forma estrictamente unifamiliar. Los únicos espacios verdaderamente comunales son los caminos y la escuela y aún cada ocasión

\footnotetext{
${ }^{6}$ Las implicaciones del sistema de nominación tradicional en la vida contemporánea son tratados en Ventura (2002 y 2009).

7 La Ley de Organización y Régimen de las Comunas está vigente desde el año 1937, con reformas en 1976 (a partir de la codificación de la misma en 1959 y de la Ley de Reforma Agraria en 1973) y en 1993.
} 
es buena para recordar que la parcela para construir esta última fue donada por un comunero particular. La imposición de la minga, decretada por el reglamento comunal, es aceptada a regañadientes y muy pocos son los comuneros que acuden a las llamadas al trabajo colectivo, prefiriendo, siempre que la economía lo permite, pagar la multa convenida como contrapartida o enviar un jornalero en su lugar. No se trata de individualismo, puesto que las leyes de reciprocidad son muy estrictas, pero las ayudas interdomésticas funcionan por la vía de la familia extensa y no por la comunal. Además, en muchas ocasiones ésta es substituida por la contratación de jornaleros no tsachila -chachis, serranos, manabitas, afroecuatorianos o colombianos- que han permitido a los tsachila adaptarse al nuevo sistema socioeconómico reduciendo el coste cultural. Junto con la práctica comercial del curanderismo, el nuevo sistema de propiedad de la tierra legislado desde el Estado ha contribuido a la implantación de una creciente desigualdad económica entre ellos, básicamente debido a la distinta cantidad de tierra que recibe cada comunero al independizarse fruto, a su vez, de la cantidad de hijos entre los que cada familia debe dividir las hectáreas de tierra que posee en usufructo.

La organización política de las comunas es quizás el elemento más relevante para el tema que aquí tratamos. El órgano representativo de la comuna es el Cabildo, que tiene por funciones: 1) autorizar la apropiación de tierras vírgenes a las nuevas familias (atribución que no es posible en ninguna de las comunas, donde la tierra libre ya se ha agotado como veíamos con anterioridad); 2) establecer los límites de las tierras que «pertenecen» a cada familia; y 3 ) representar a la comuna -y al conjunto de familias que la constituyen- ante el estado nacional (CAAP 1985: 106-108). De estas funciones, sólo la última sigue teniendo vigencia, y de alguna manera se superpone a la atribución de poderes del gobierno étnico del que hablaremos más abajo. El Cabildo está formado por un presidente, un vicepresidente, un tesorero, un síndico y un secretario, elegidos anualmente, y cuyas resoluciones se toman previa audición de la asamblea general de comuneros (Art.8, 15 y 16 de la Ley de organización y régimen de las Comunas y Estatuto de las comunidades campesinas). Especialmente el presidente adquiere una relevancia particular en las comunas tsachila, sin por ello convertirse en la figura eminente que representa el gobernador o todavía los chamanes actuales. Los presidentes y el resto de miembros del Cabildo son elegidos por su capacidad de dominio de la lengua española, de las estrategias de negociación para con el mundo exterior, por su capacidad de escribir correctamente, y de administrar las cuentas del erario público y a veces por otras razones que tienen más relación con la lógica de la reciprocidad que con la capacidad real de estas figuras. En esta última situación, el equipo de gobierno comunal debe integrar personas con las aptitudes anteriormente reseñadas. La opinión del presidente en asuntos internos no suele ser más escuchada que la de otros miembros de la comuna, y sus decisiones son a menudo puestas en tela de juicio, por lo que sus mandatos sólo superan el año de vigencia cuando no existen candidatos para la renovación. Fuera de los inicios, en que la presidencia de las comunas recaía en los grandes líderes, coincidiendo con las personas que habían llevado a cabo el proceso de negociación y constitución de las mismas, actualmente pocas veces los presidentes de comuna son personas carismáticas o que adquieren presencia en los ámbitos extracomunales. A veces otras personas relevan- 
tes en la comunidad son más escuchadas que los propios miembros del Cabildo: se trata de los que antes hemos denominado «líderes de facto», y que pueden ser desde ancianos, chamanes o jóvenes conocedores de los mitos, traductores, personas vinculadas con algunos organismos exteriores (consejo provincial, iglesia), etc.

Paralelamente al gobierno comunal, que emana de las leyes y organización del Estado, existe el gobierno étnico, que abarca al conjunto de los tsachila. El primer gobernador reconocido legalmente por la Presidencia del Ecuador en 1971 fue Abraham Calazacón, aunque en el texto donde se reconocía, se señalaba que dicho gobernador ejercía de facto su liderazgo desde veinticinco años antes. Por otro lado, la memoria oral recuerda a su progenitor, Alejandro Calazacón, como antecesor suyo, al ser también reconocido de facto como representante del grupo. En 1975 se aprobaron los primeros Estatutos, entonces denominados Estatutos de la Tribu de los Indios Colorados, que serían reformados en 1983 y con posterioridad en 1996, cuando ya pasaron a denominarse Estatutos de la Comunidad Tsachila ${ }^{8}$.

Podríamos señalar que la redacción de los Estatutos poco tuvo que ver con la «pluma» indígena ${ }^{9}$. En su primera versión, aprobada en 1975, se recogen algunas de sus problemáticas más acuciantes, como la malversación de bienes comunales por parte de los comuneros, el matrimonio interétnico, las necesidades materiales de mejora de caminos y campos deportivos, y la posibilidad de financiarse con organismos exteriores, o el alcoholismo, además de la insistencia en promover el turismo en su zona. En ella se declara a los tsachila patrimonio turístico nacional, se les conmina a conservar las características más externas de su identidad -como la costumbre de pintarse el cabello de rojo para los hombres o de vestirse con su atuendo típico las mujeres-, y a promover el turismo en su zona, al tiempo que se regulan los matrimonios endogámicos -con la prohibiciones de contraerlos interétnicos en la reforma del 1983-, y se regula de forma absolutamente detallada las infracciones a la «moralidad», con multas precisas. Los estatutos reglamentan igualmente las funciones del gobernador y su sistema de transmisión, vitalicio. En ellos se hace también referencia a la posibilidad de que los miembros de la «tribu» establezcan relaciones institucionales con organismos exteriores, de carácter público o privado, entre los que se contemplan los «demás organismos de indígenas» (Art. 50).

En la versión de 1983 se insiste en nuevas problema añadidos, se prohíbe definitivamente los matrimonios interétnicos -redefiniendo quien es y quien no puede ser tsachila, es decir, pertenecer a la Tribu de Indios Colorados-, se decreta la obligación de llevar a los hijos a la escuela -introducida por aquellas fechas pese a la oposición de muchos de los mayores- y se regula el ejercicio del curanderismo, esto último para prevenir la intromisión de los curanderos con «ética comercial» que compiten deshonestamente con los tradicionales, a veces aún sin ser indígenas y haciéndose

\footnotetext{
8 La elección de este término fue fruto de un largo debate y votación asamblearia, donde la alternativa de «nacionalidad»-propuesta por el sector más implicado con la CONAIE- fue desestimada (aunque finalmente es de uso actual). Nótese la diferente percepción del colectivo respecto de otros grupos, que prefirieron este último término. Añadamos también que muchos comuneros desconocían las implicaciones ideológicas y políticas de ambos conceptos en discusión. En la decisión probablemente se valoró más el sector de poder interno del cual emanaba cada una de las propuestas que el propio contenido de las mismas.

9 Se trata de textos jurídicos, firmados por la totalidad de miembros del consejo de gobernación -es decir, el gobernador y los tenientes por él elegidos de cada comuna- con la huella dactilar de sus pulgares derechos.
} 
pasar por tales, otras usando métodos poco autóctonos para atraer a la clientela (como los «chimberos», o instalarse fuera de la comuna a pie de carretera). Este tema es de suma importancia y reaparecerá en la reforma de 1996, cuando previa aprobación, uno de los mayores temas de discusión, que después se desestimó, fue la prohibición, para los curanderos vegetalistas que no seguían la tradición, de presentarse como candidatos a la Gobernación, extremo que podía leerse con nombre y apellidos.

Aquí encontramos una de las paradojas más relevantes. Como señalaron en su momento un grupo de investigadores ecuatorianos (CAAP 1985), los primeros Estatutos estaban teñidos de exotización y de una aparente regulación de la tradición. Pero subyace en ellos una normativa de autogobierno superior al que gozaba ningún otro de los grupos indígenas del Ecuador, con jurisdicción casi total sobre sus miembros de forma paralela a la del Estado. A pesar de ello, raras veces los tsachila han aprovechado en toda su plenitud dicha atribución. Cuando no hay acuerdo con la sanción o decisión tribal, los individuos como ciudadanos tienen pleno derecho a recurrir a la justicia que emana del estado del que forman parte.

Para concluir este apartado, conviene señalar un último aspecto. Tal como apuntábamos con anterioridad, Brown y Chaumeil han expuesto la transformación en la organización política de las sociedades amazónicas, resaltando la creación de un multiliderazgo donde el sistema tradicional -los chamanes y antiguos jefes- pierde parte de sus atribuciones, y el nacimiento de nuevos líderes, jóvenes preparados formalmente para su desenvolvimiento en la sociedad nacional. En aquel caso, un mismo sistema acogía ambas formas de gobierno. En el caso tsachila, observamos esta duplicidad perfectamente delimitada en las dos formas de gobierno con las que se rigen, el étnico y el comunal. De alguna forma, podríamos decir que el étnico mantiene, con sus adaptaciones, la filosofía del liderazgo tradicional, mientras que el comunal ha generado, con matices, el nuevo tipo de líderes que articulan en la actualidad las organizaciones indígenas en todo el país. Sin embargo, tampoco son los presidentes de cabildos comunales - no formados para la lucha indígena, ni siquiera en el llamado «desarrollo comunitario»- los representantes del grupo étnico tsachila en las federaciones indígenas regionales y en la CONAIE. La limitación de la participación tsachila en estos organismos debe aquí también ser argumentada.

\section{Relaciones con la CONAIE}

Junto con los chachi y los awa -y últimamente un pequeño grupo de epera procedentes de Colombia-, los tsachila forman parte de las llamadas etnias reconocidas del occidente de los Andes ecuatorianos, con lengua propia y atributos identitarios y culturales específicos. En la organización indígena de la Costa (CONAICE) participan además, y de forma especialmente activa, los huancavilcas, indígenas de la Península de Santa Elena, caracterizados por ciertos sectores como «indios invisibles», que reclaman en las últimas décadas su adscripción étnica (cf. Álvarez 1999), a los que se han sumado los manteños y en algunas clasificaciones se incluyen los montubios y la población afroesmeraldeña. 
A diferencia de otros grupos amazónicos, como el destacado caso de los shuar, los tsachila no tuvieron una misión católica fuerte en su seno en los últimos cincuenta años. La misión que ocupó su territorio por casi medio siglo fue el Instituto Lingüístico de Verano, con una filosofía para con los grupos indígenas mucho más tendente a la fragmentación que a la lucha unitaria. La renovación que provocó en el mundo misional católico la Teología de la Liberación, y que abrió en muchos grupos étnicos la posibilidad de lucha por sus derechos étnicos, no se dio entre los tsachila. El evangelismo promovió una ideología contraria, promulgando la demonización de las federaciones indígenas y asociándolas al comunismo. En 1991 los misioneros del ILV se estaban retirando de sus comunidades a raíz de la expulsión oficial del país promulgada un par de años antes y los tsachila sólo mantenían una débil vinculación con el movimiento indígena nacional, que sin embargo ya había protagonizado un renombrado Levantamiento Indígena, el del llamado Inti Raymi en 1990 (cf. Moreno Yánez y Figueroa 1992). Esta vinculación pasaba por el único sector gestionado por la iglesia católica: la educación secundaria y el programa de formación de profesores indígenas, más tarde denominado intercultural bilingüe, que se desarrollaba en la Escuela de la Madre Laura en el propio Santo Domingo de los Colorados (ahora Santo Domingo de los Tsáchila). Este Colegio formó los primeros profesores indígenas cuando se puso en marcha el programa de educación bilingüe en las comunidades tsachila en el último decenio del siglo XX y es a partir de este programa que se institucionaliza la vinculación de los tsachila al colectivo indígena nacional. Por ello veremos cómo los primeros años la participación tsachila en los movimientos de las agrupaciones indígenas y particularmente de la CONAIE se limita a la representación del profesorado en actos directamente relacionados con la Educación Bilingüe. Este sector, formado ideológicamente en la lucha indígena, se ve confrontado sucesivamente a los poderes internos reacios a dicha lucha, y sus actuaciones son permanentemente puestas en tela de juicio. Consiguen sin embargo cierta relevancia en el asesoramiento de la gobernación durante los últimos años del primer mandato de Nicanor Calazacón, en que la Federación de la Costa, entonces COICE, se pone efectivamente en marcha. Pero pasan nuevamente a la oposición cuando los Estatutos son reformados en 1996, se convocan elecciones y éstas son ganadas por uno de los grandes curanderos poco interesados en esta lucha. Mientras tanto, ya han ganado espacios en el ámbito nacional y algunos de ellos trabajan como miembros liberados de las instancias administrativas y gestoras de la sección intercultural bilingüe de la CONAIE. A partir de ahí se produjo un conflicto por la representación externa, que se evidenció en las manifestaciones públicas de los tsachila en los órganos indígenas regionales. Resultado de aquel conflicto, el gobernador fue destituido y después de un período de incertidumbre, de gobiernos en funciones, de visibilización de los desacuerdos ante las cámaras, se reeligió, ya no de forma vitalicia, a Nicanor Calazacón como gobernador del nuevo período, el cual fue nuevamente sustituido por otros gobernadores no vitalicios sucesivos, Héctor Aguavil y Gumercindo Aguavil. Aquel conflicto, que dio una imagen de desunión al grupo étnico tsachila o, lo que es más incorrecto, de lucha por el poder, debería ser analizado en el marco de su forma tradicional de organización socio-política, antes reseñada, y en el contexto de la historia regional del último siglo para ser entendido en su justa dimensión. 


\section{Reflexiones finales}

En este contexto de deficiencia de penetración estatal así como de escasa lucha política desde la perspectiva étnica, y vistos otros casos, el puente de unión lógico con el mundo global debería haber sido la cooperación internacional y particularmente las ONG's para el desarrollo. También en eso los tsachila se presentan como un contraejemplo. Como señalaba en un texto breve una década y media atrás (Ventura 1996b), la tipología específica del liderazgo indígena viene asociado en el caso tsachila con una deficiencia en proyectos de desarrollo. Por otro lado, por razones que Víctor Bretón ha analizado en el caso andino ecuatoriano (Bretón 2001), la visibilidad indígena y una buena estructura de organizaciones de base puede contribuir, más que la necesidad material, a que las organizaciones no gubernamentales de cooperación al desarrollo decidan trabajar en unas regiones y no en otras. Los tsachila no cumplen aquel último requisito, a saber, el tejido organizativo que la sociedad global les requiere, y que sí cumplen los indígenas andinos; presentan, eso si, una identidad étnica patente, al igual que sus compatriotas amazónicos, pero a diferencia de éstos, adolecen de un entorno medioambiental degradado que los pone en situación de desventaja ante la «competencia» que en este sentido significa la Amazonía, en un contexto internacional de priorización de proyectos de matiz ecologista, especialmente por tratarse de un grupo indígena de tierras bajas. Todavía ahora, una década después de iniciado el siglo XXI, se podrían contar con los dedos de las manos los proyectos no gubernamentales destinados a favorecer las condiciones de vida de esta sociedad. Junto con la degradación medioambiental, el menor appeal exótico de sus miembros, un sistema de liderazgo por adaptar al de las organizaciones indígenas más politizadas y una ausencia del Estado y sus servicios, el grupo indígena tsachila sigue resistiendo en soledad ante los nuevos retos de esta centuria.

\section{Referencias bibliográficas}

Álvarez, Silvia Graciela

1999 De Huancavilcas a comuneros. Relaciones interétnicas en la Península de Santa Elena, Ecuador. Quito: Abya-Yala.

BRETÓN, Víctor

1997 Capitalismo, reforma agraria y organización comunal en los Andes. Una introducción al caso ecuatoriano. Espai/Temps $n^{\circ} 29$. Lleida: Universitat de Lleida.

2001 Cooperación al desarrollo y demandas étnicas en los Andes ecuatorianos: ensayos sobre indigenismo, desarrollo rural y neoindigenismo. Quito y Lleida: FLACSO y Universitat de Lleida.

Brown, Michael F.

1993 «Facing the State, Facing the World: Amazonia's Native Leaders and the New Politics of Identity», en «La remontée de l'Amazone». L'Homme 126-128: 307-326. doi: $10.3406 /$ hom. 1993.369642 


\section{CAAP}

1985 «De Tsachilas a campesinos: apuntes para el conocimiento del proceso de transición», en Del indigenismo a las organizaciones indígenas, pp. 91-117. Quito: Abya-Yala.

Chamoux, Marie-Noëlle y Jesús Contreras (eds.)

1996 La gestión comunal de recursos. Economía y poder en las sociedades locales de España y América Latina. Barcelona: Icaria - Institut Català d'Antropologia.

Chaumeil, Jean-Pierre

1990 «'Les nouveaux chefs...': pratiques politiques et organisations indigènes en Amazonie péruvienne». Problèmes d'Amérique Latine 96: 93-113.

Clastres, Pierre

1974 La société contre l'État. París: Éd. de Minuit.

1980 Recherches d'Anthropologie Politique. París: Éd. du Seuil.

Descola, Philippe

1988 «La chefferie amérindienne dans l'anthropologie politique». Revue Française de Science Politique 38 (5): 818-827.

Díez Hurtado, Alejandro

1991 «Las comunidades indígenas en el bajo Piura, Catacaos y Sechura en el siglo XIX», en Los Andes en la encrucijada. Indios, comunidades y Estado en el siglo XIX, H. Bonilla, comp., pp. 169-198. Quito: Libri-Mundi - Enrique GrosseLuemern /FLACSO Sede Ecuador.

Estatutos de la Tribu de los Indios Colorados

1975 Santo Domingo de los Colorados.

1983 Santo Domingo de los Colorados: Editora Saltos.

Golte, Jurgen

1992 «Los problemas con las 'Comunidades'». Debate Agrario 14: 17-22. Lima.

Guerrero, Andrés

2000 «El proceso de identificación: sentido común ciudadano, ventriloquía y transescritura», en Etnicidades, A. Guerrero, comp., pp. 9-60. Quito: FLACSO-Ecuador / ILDIS.

Helms, Mary W.

1980 «Succession to high office in Pre-Columbian circum-Caribbean chiefdoms». Man 15 (4): 718-731.

JOUANEN, José

1941 Historia de la Compañia de Jesús en la Antigua Provincia de Quito 1570-1773. Tomo I (1570-1696). Quito: Ed. Ecuatoriana.

KradOLFER, Sabine

2011a «(Self)essentialization of cultural differences: how peoples and states play hideand-seek». Anthropological Notebooks 17 (2): 37-53.

$2011 \mathrm{~b}$ «The transnationalisation of indigenous peoples' movements and the emergence of new indigenous elites». International Social Science Journal 202: 377-388.

Ley de Organización y Régimen de las Comunas y Estatuto de las Comunidades Campesinas 1993 Quito: Corporación de Estudios y Publicaciones. 
López GarcíA, Julián y Manuel GutiÉrRez Estévez (coords.)

2009 América indigena ante el siglo XXI. Madrid: Fundación Carolina / Siglo XXI.

Marcos Pino, Jorge G.

1988 Real Alto: La historia de un centro ceremonial Valdivia. Primera parte. Biblioteca Ecuatoriana de Arqueología 4. Quito: Corporación Editora Nacional.

2005 «Chamanismo y sacrificio en Real Alto: antecedentes del ritual andino en el Formativo temprano del antiguo Ecuador», en Chamanismo y sacrificio. Perspectivas arqueológicas y etnológicas en sociedades indígenas de América del Sur, J.-P. Chaumeil, R. Pineda Camacho y J.-F. Bouchard, eds., pp. 105-122. Bogotá: Fundación de Investigaciones Arqueológicas Nacionales, Banco de la República / Instituto Francés de Estudios Andinos.

Martínez Mauri, Mònica

2009 «Ruben Pérez Kantule: la diplomatie autochtone avant les ONG à Kuna Yala (Panama)», en Luttes autochtones, trajectoires postcoloniales, B. Bosa y E. Wittersheim, dirs. Paris: Karthala.

2010 «Puentes en las fronteras. Identidad y mediadores culturales kunas», en Fronteras y mestizajes. Sistemas de clasificación social en Europa, América y África, M. Ventura i Oller, ed., pp. 85-97. Bellaterra: Universitat Autònoma de Barcelona.

Martínez Mauri, Mònica y Eugenia Rodriguez Blanco (eds.)

2008 Intelectuales, mediadores y antropólogos. La traducción y la reinterpretación de lo global en lo local. Donostia: Ankulegi.

Moreno YÁnez, Segundo y José FigueroA

1992 El levantamiento indigena del Inti raymi de 1990. Quito: FESO / Abya-Yala.

Navas de Pozo, Yolanda

1990 Angamarca en el siglo XVI. Quito: Abya-Yala.

Roosevelt, Anna C.

1993 «The Rise and Fall of the Amazon Chiefdoms», en «La remontée de l'Amazone». L'Homme 126-128: 255-283.

StOLCKe, Verena

1997 «The 'Nature' of Nationality», en Citizenship and Exclusion, V. Boder, ed., pp. 61-80. Basingstoke: Macmillan Press.

STOTHERT, Karen E.

2003 «Expression of Ideology in the Formative Period of Ecuador» en Archaeology of Formative Ecuador, J. Scott Raymond y Richard L. Burger, eds., pp. 337-421. Washington: Dumbarton Oaks Research Library and Collection.

URRUTIA, Jaime

1992 «Comunidades campesinas y antropología: historia de un amor (casi) eterno». Debate Agrario 14: 1-16. Lima.

Ventura i Oller, Montserrat

1996a «La organización comunal en un grupo indígena de las tierras bajas: el caso Tsachila del Occidente ecuatoriano», en La gestión comunal de recursos. Economía y poder en las sociedades locales de España y América Latina, M.-N. Chamoux y J. Contreras, eds., pp. 439-473. Barcelona: Icaria / Institut Català d'Antropologia. 
1996b «El liderazgo indígena y la cooperación internacional», en Antropología social de América Latina, VII Congreso de Antropología Social, Simposio VI, Carlos M. Caravantes, coord., pp. 41-45. Zaragoza.

1997 «Una visión de la cultura Tsachila en la actualidad», en Etnografias mínimas del Ecuador, M. Ventura et al., pp. 1-32. Quito: Abya-Yala.

1999 «Ser Tsachila en el Ecuador contemporáneo: un análisis desde la antropología». Ecuador Debate 48: 95-118.

2002 «Verdades relativas. Reflexiones en torno a la comprensión del mundo. El caso tsachila del Ecuador», en Identidades, relaciones y contextos, J. Bestard Camps, comp., pp. 115-128. Barcelona: Dept. d'Antropologia i d'Història d'Amèrica i Àfrica, Universitat de Barcelona.

2009 Identité, cosmologie et chamanisme des Tsachila de l'Équateur. À la croisée des chemins. Paris: L'Harmattan.

2011 «Redes chamánicas desde el punto de vista Tsachila», en «Salud y enfermedad en América Latina desde la perspectiva intercultural», F. M. Gil García, coord. Nuevo Mundo Mundos Nuevos, Debates. Documento electrónico, <http://nuevomundo. revues.org/61200>, con acceso el 15/11/2011.

Vila i Mitjà, Assumpció, Ivan Briz, Débora Zurro y Andrea Toselli

2006 «Trasvase acrítico de categorías etnográficas a la práctica arqueológica», en Etnoarqueología de la prehistoria: más allá de la analogía, pp. 337-348. Madrid: Consejo Superior de Investigaciones Científicas. 